\title{
An Innovative Interprofessional Assessment
}

\author{
Ruth Strudwick \\ University of Suffolk, United Kingdom \\ Jane Harvey-Lloyd \\ University of Suffolk, United Kingdom
}

\begin{abstract}
This article describes and evaluates the assessment used for a UK-based module entitled IPL Working with Others. The module was attended by 320 students from adult nursing, child health nursing, mental health nursing, midwifery, social work, operating department practice, diagnostic radiography and therapeutic radiography. Students were divided into interprofessional groups of eight students. The groups were given a case study of a service user coming into contact with different health and social care professionals. They had to work together to produce a poster, based on the case study. The interprofessional groups provided a 'real' experience of working together and understanding one another's roles. The students then had to defend their poster as a group and respond to questions from two assessors. In order to review the assessment, both students and staff were asked to provide feedback about the assessment process, listing the positive and challenging aspects. All of the staff provided feedback (12), and $192(60 \%)$ students also provided feedback. It was found that the assessment worked well, both staff and students having found it to be both a good learning experience as well as being a good way to assess IPL. Students had a 'real' experience of interprofessional working, facing barriers and challenges to overcome which are similar to those in practice.
\end{abstract}

\section{Keywords: assessment; group work; interprofessional education; interprofessional learning; presentation}

${ }^{*}$ Corresponding Author: Dr Ruth Strudwick, University of Suffolk, Waterfront Building, Neptune Quay, Ipswich, IP4 1QJ United Kingdom

Email:r.strudwick@uos.ac.uk

Journal URL: http://e-learning.coventry.ac.uk/ojs/index.php/pblh

Strudwick, R. and Harvey-Lloyd, J. (2016) 'An innovative interprofessional assessment'. International Journal of Practice-based Learning in Health and Social Care, 4 (2), 88-100

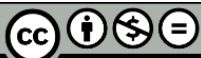

BY NC ND (c) 2016 Ruth Strudwick and Jane Harvey-Lloyd. This Open Access article is distributed under the terms of the Creative Commons Attribution Attribution-Non-Commercial No Derivatives 4.0 International License (https://creativecommons.org/licenses/by-nc-nd/4.0/), which permits unrestricted noncommercial use, distribution, and reproduction in any medium, provided the original work is properly cited and is unaltered. 


\section{Introduction}

In the first decade of the 21 st century, policies about the perceived value of interprofessional education and learning became evident in the UK (Department of Health 2000, Department of Health 2001, Department of Health 2005). Within higher education institutions (HEls), it is important to define what is meant by interprofessional education (IPE) and interprofessional learning (IPL). The definition of IPE and IPL adopted at the HEI providing the focus for this study is that provided by the UK Centre for Advancement of Interprofessional Education (CAIPE), which defines IPE and IPL as occurring when "two or more professions learn with, from and about one another to improve collaboration and quality of care" (CAIPE n.d.). This definition is used to inform and adapt the curricula within which IPL takes place.

This article describes and evaluates the assessment within an interprofessional learning module delivered to first year health and social work students in the UK. The article outlines the assessment and its evaluation, discussing the themes that were identified from analysis of the evaluation questionnaire.

\section{Background literature}

A search of the literature was carried out using the search terms 'interprofessional', 'assessment' and 'working together'.

Since 2000, there has been a great deal written about IPL in pre-registration education within health and social care. Writers have focussed on the impact of IPE on team working and stereotyping (Ateah et al. 2010, Bell and Allain 2011). It has been difficult to quantify the long term impact of IPL on interprofessional working in practice (Cooper et al. 2001, Hammick et al. 2007, Lapkin, Levett-Jones, and Gilligan 2013). However, it is acknowledged that IPL should have a positive effect on practice and the way in which health and social care professionals work together. The principle of IPE is that if health and social care students learn together, then they should be better prepared for interprofessional team work in the practice environment which should lead to improved care of the service user (Barr et al. 2005). This needs to start in the university setting for students to ensure that IPL improves the safety of service users through improving communication and collaboration between professionals (Barr and Low 2012). However, the evidence in support of the effect of IPL on practice and patient care tends to be anecdotal, rather than empirical (Lapkin, Levett-Jones, and Gilligan 2013). Educators and practitioners agree that the care of the service user is paramount and that interprofessional collaboration should improve this care. A team approach is vital so that professionals with different areas of expertise can respond collaboratively to complex problems thus ensuring optimum care for all service users along their care pathway (Barr and Low 2012).

Teamwork is a key aspect of successful interprofessional working. Therefore team working should be promoted, and indeed be a key part of IPL, so that students see its importance. In the case of health and social care professionals, the team should be working towards a common goal: the care of the service user (Martin, Charlesworth, and Henderson 2010). Teams are successful when all of the members work cohesively but this can be a challenge when team members are from different professional backgrounds. In some teams, there can be misunderstandings of the roles of others and this can cause tensions (Shaw, de Lusignan, and Rowlands 2005). Interprofessional rivalry and tribalism can also occur where professionals are working with different professionals in a team (Mandy, Milton, and Mandy 2004). The language and terminology used by different professional groups can also be a barrier to working together, and so it is important that all members of the group understand the language and terminology used (Welsh 2012). If these tensions are 'ironed out' within the university setting, this should lead to a greater understanding of one another within the practice environment.

In terms of pre-registration education, several authors have promoted the use of team work in IPL within the university setting. Gilligan, Outram and Levett-Jones (2014) found that recent 
graduates valued the IPL experiences that involved genuine engagement and opportunities to interact with students from other professions to look at a relevant problem. They felt that these experiences prepared them well for practice and enjoyed looking at case studies or scenarios where they could learn about the roles of other professionals and how they contributed to the given case study or scenario (Gilligan, Outram, and Levett-Jones 2014). Shared learning about a specific case study is critical to the effectiveness of IPL (Kilminster et al. 2004).

Mellor, Cottrell and Moran (2013) also found that students welcomed the opportunity to learn the roles of other professions and their contributions to the team. Mellor, Cottrell, and Moran (2013) used case studies as part of the IPL programme and students recognised the importance of an interprofessional approach and the valued contributions of each professional group. This allowed students to make theory-to-practice links and apply what they had learnt to professional practice.

Some students were surprised that the others wanted to learn more about their roles. However, by explaining their role to others, the students were prompted to reflect on what they did and their area of expertise (Mellor, Cottrell, and Moran 2013). This turned out to be an important part of the students learning: developing an appreciation of what other professionals did, their role, and responsibilities and how they each contributed to the patient pathway.

Kilminster et al. (2004) used patient-focussed interprofessional workshops in their small-scale study. One of the participants in this study said "I learnt about what is going on in other health professionals' minds when they ask you to do something, what they are expecting you to do" (Kilminster et al. 2004:720). The students were enabled to increase their knowledge and awareness of the expertise that other professionals had, and understand who they could ask for advice in the future. Problem-based learning based on case studies is also advocated by McKee, D'Eon, and Trinderk (2013). They suggest that such case studies create positive learning as they are experimental, co-operative and based on service user cases.

Stone (2010) provides an argument for the formal assessment of IPL. She suggests that this will ensure that students recognise its importance and relevance to their future practice. She proposes that IPL assessment should utilise assessment tools which make student collaboration essential. Stephens, Robinson, and McGrath (2013) suggest that group learning and assessment using online tools has benefits for the students. By engaging online, the students do not have to deal with a loss of face if they have the wrong answer; the group becomes more cohesive and motivated if they all engage; and quieter students can engage more confidently (Stephens, Robinson, and McGrath 2013). However, this is only successful if all students engage in the process and become involved. Incorporation of a wiki into the assessment process, encourages more regular use by students and engagement with the process (Parsell and Bligh 1998, Reeves 2000).

Stone (2010) also makes a case for the use of group work that is designed to replicate or simulate the workplace to make learning authentic. Students can become frustrated about group work assessment and so this needs to be managed carefully (Purchase 2000). Group work can be assessed in a combined way utilising observer, self and peer review (Cheng and Warren 2000). Peer assessment can be approached as a learning exercise in itself, encouraging further collaboration (Purchase 2000, Stone 2010). Self-assessment can be used to develop reflective skills which are useful when working in a team environment, and can aid in self-awareness. The assessment needs to be carefully managed so that it suits the needs of all of the students from different professional groups (Dunworth 2007).

Overall, it has been established that IPL should allow for deep and rich learning experiences (Stone 2010). Students should learn from and about one another (CAIPE n.d.), and learn to work in interprofessional teams with a common goal: the care of the service user (Martin, Charlesworth and Henderson 2010). The use of case studies that replicate practice and problem-based learning in IPE enhance the learning and allow students to learn about one another's roles in the team (Kilminster et al. 2004, McKee, D'Eon, and Trinderk 2013). Formally 
assessing IPL allows for greater engagement from students (Stone 2010), and the use of online tools - such as a wiki - increases student engagement with group work (Parsell and Bligh 1998, Reeves 2000, Stephens, Robinson, and McGrath 2013). IPL assessment needs to be designed and managed to meet the competencies required by all students from each professional group engaged in IPL (Dunworth 2007).

\section{Study context}

This article describes and evaluates the assessment used for one of the IPL modules delivered at our university to first year health and social care students. The module is entitled IPL Working with Others. In total, there were 320 students enrolled on the module from the following professional groups: adult nursing, child health nursing, mental health nursing, midwifery, social work, operating department practice, diagnostic radiography and therapeutic radiography.

This module introduces the principles of interprofessional working, contextualising each student's growing professional identity within the broader interprofessional arena. The overall aim of the module is for the student to engage in effective professional relationships with colleagues and service users.

For the delivery and the assessment of the module, students were divided into interprofessional groups with eight students in each group. All group members were purposefully selected to ensure a good interprofessional mix in each group, so students were allocated into groups manually to ensure that as many different professions as possible were represented in each of the groups. At the start of the module, the groups were provided with a case study of a service user who came into contact with several different health and social care professionals during their case pathway. The students had to work together to produce a group poster, based on the case study, and were then required to defend their poster as a group, answering questions from two assessors about their poster and their learning experience. See Figure 1 for the assessment criteria for the group poster and the presentation.

Figure 1: Assessment criteria for the group poster and presentation

\begin{tabular}{|l|l|}
\hline POSTER & Weighting \\
\hline Assessment criterion & $15 \%$ \\
\hline $\begin{array}{l}\text { Demonstrate the complexity of delivering effective service user centred care } \\
\text { in an interprofessional environment }\end{array}$ & $15 \%$ \\
\hline $\begin{array}{l}\text { Present the information on the poster clearly and logically, using professional } \\
\text { language }\end{array}$ & $10 \%$ \\
\hline $\begin{array}{l}\text { Produce a poster that contains appropriate original, visual material, } \\
\text { annotated appropriately }\end{array}$ & $10 \%$ \\
\hline $\begin{array}{l}\text { Produce work which demonstrates presentation, grammatical and } \\
\text { referencing skills consistent with level 4 criteria. }\end{array}$ & $15 \%$ \\
\hline Poster defence & $15 \%$ \\
\hline Discuss the issues relating to working within an interprofessional team \\
\hline $\begin{array}{l}\text { Articulate the challenges of delivering effective service user care in an } \\
\text { interprofessional environment }\end{array}$ & $10 \%$ \\
\hline $\begin{array}{l}\text { Understand the roles of the professions represented in their group and in the } \\
\text { given case study }\end{array}$ & $10 \%$ \\
\hline $\begin{array}{l}\text { Reflect on their own practice and understand their role within the } \\
\text { interprofessional team }\end{array}$ & \\
\hline
\end{tabular}


This group presentation lasted for 20 minutes and ensured that all members of the group met the learning outcomes of the module which can be seen in Figure 2. The interprofessional groups provided a 'real' experience of working together and understanding one another's roles in context (CAIPE n.d.).

Figure 2: Aims and learning outcomes for the module

\section{Aims}

1) To develop an understanding of their own professional identity;

2) To develop an awareness of each other's role within the interprofessional team;

3) To understand the importance of interprofessional communication and team working;

4) To appreciate the complexity of delivering effective service user centred care in an interprofessional environment.

\section{Learning Outcomes}

Upon successful completion of this module, the student will be able to:

1) Understand their role within the professional team;

2) Learn from and about other professionals;

3) Demonstrate the fundamental communication skills and principles necessary to facilitate effective relationships with colleagues from different professional groups and to care for service users;

4) Reflect on their own practice within the interprofessional team.

The contributions of individual students in terms of materials, information and draft documentation were made available to the markers via a wiki. The wiki allowed for tracking of contributions made by individual students, and the assessors and other group members could see how much each student had put onto the wiki. A final electronic version of the poster was submitted which contributed to the grade awarded. The group's poster and defence were assessed, and overall feedback was provided to the group as a whole. As an integral part of the interprofessional learning, the group members engaged in a discussion with their peers and the assessors in order to evaluate their own - and others' - contribution to the poster and presentation. This discussion was taken into account by the markers alongside the evidence of contributions to the work via the wiki when allocating the final grade for each individual student. For example, in some groups there were individual students who had contributed more than others, and so the group decided that they should be awarded a higher mark. There were also some students who, it was felt, had contributed less to the assessment and therefore the group awarded them a lower grade.

\section{Methodology}

This study was a prospective, cross-sectional evaluation of the module assessment. As stated earlier, the students were allocated into interprofessional groups of eight students.

In order to review the assessment, all students (320), and the staff assessing the students (12), were asked to complete a short questionnaire to provide qualitative feedback about the assessment process. The questionnaire asked them to note the positive and challenging aspects of the assessment from their own perspective, and to also provide suggestions and recommendations for the future. They were encouraged to write free comments and to give their own opinions. 
This type of research tool has a number of advantages such as ease of completion, low cost, straight-forward data analysis, and the ability to collate data effectively (Gillham 2000). The purpose of the questionnaire was to gather the opinions of the students and staff members about the assessment, and to collate suggestions and recommendations for the future. The data were analysed using a thematic analysis.

The evaluation formed part of the university's on-going module evaluation, and therefore ethical approval was not deemed necessary. The chair of the ethics committee has approved the publication of these findings.

\section{Results and discussion}

All twelve of the staff provided feedback, and 192 students (60\%) also provided feedback.

The findings were analysed by both researchers using a thematic analysis. The researchers looked through the questionnaire responses together and identified themes. Themes were identified from both the student and staff feedback. One of the themes came only from the students (communication in the groups), all of the other themes came from both the students and the staff members. These themes highlighted trends within the data and subjects that were discussed by the participants.

There were six themes identified from the feedback:

- Communication in the groups;

- Learning each other's roles;

- Real issues from practice uncovered;

- Working together;

- Making it relevant to all;

- The assessment was also a learning experience.

\section{Communication in the groups}

The students had time during the module delivery to meet up, and they also had a wiki and discussion board that they could use to email one another. However, because the students were on different courses and had different patterns of attendance both at university and in practice, it was difficult at times for them to meet up with, and communicate with, the group. This was considered by many of the students as a challenge of the assessment.

It was difficult to meet face to face as we all had different commitments.

Student feedback.

We couldn't find a time when we could all meet, so we used email and the wiki.

Student feedback.

It was difficult as we couldn't practice the presentation beforehand.

Student feedback.

Interestingly, some of the students pointed out that this was very similar to the tensions experienced in practice when trying to communicate with or share information with other professionals (Shaw, de Lusignan, and Rowlands 2005).

This was a bit like practice, we could all be working different shifts.

Student feedback.

Group communication difficulties may be due to working different shift patterns, working in a different organisation, not being able to speak on the phone, or difficulty in sharing information between different computer systems. In essence, we had created a situation that mirrored 
practice and prepared the students well for the tensions of trying to communicate with other professionals in the practice environment.

The use of the wiki did help the students in their communication with one another as they were able to share ideas and resources to assist them in the creation of their poster and in planning the presentation. Stephens, Robinson, and McGrath (2013) suggest that the use of a wiki for group work encourages the group to become more cohesive and motivated, and that the use of online learning tools are believed to increase interest and ownership in the subject matter.

Students also commented on the use of professional language and jargon in their groups.

We had a rule in our group that we would challenge each other if we didn't understand language, jargon or abbreviations used - this worked well.

Student feedback.

Students also said that they had to ask other students to explain some of the terminology that they were using. This is common in interprofessional teams, and has been found in other studies (Welsh 2012). Although this was expressed as a challenge, it could be argued that this was actually beneficial to the students as they were able to reflect on their use of professional language and jargon. This allowed the students to think about the language that they use to communicate with colleagues from other professional groups.

This theme demonstrated that Learning Outcome 3 from the module descriptor (Demonstrate the fundamental communication skills and principles necessary to facilitate effective relationships with colleagues from different professional groups and to care for service users) was being met through the assessment process.

\section{Learning each other's roles}

As a result of the module and the assessment, the students said that they had learnt about each other's roles.

The students demonstrated a clear understanding of the roles of the other professionals in their group.

Staff feedback.

I now know what an ODP does!

Student feedback.

The assessment had provided them with a greater understanding of the roles of each of the other health and social care professionals studying on the IPL module (Mellor, Cottrell, and Moran 2013, Gilligan, Outram, and Levett-Jones 2014). The students said that by learning one another's roles, they were able to better understand the patient pathway, and to see where each profession fitted into the pathway and how they could each have an input influencing the care given to the patient; this is similar to the findings from the study by Kilminster et al. (2004). This was encouraging feedback from the students, and demonstrated that Module Aim 2 (To develop an awareness of each other's role within the interprofessional team) was being met, fitting with Learning Outcomes 1 and 2:

- Understand their role within the professional team

- Learn from and about other professionals.

This awareness of others also heightened the student's awareness of their own professional role within an interprofessional team, developing an understanding of their own professional identity (Module Aim 1).

The group assessment gave me an insight into the roles of other people.

Student feedback. 
Both the students and the staff members commented that this group assessment allowed students to learn from and about one another, and therefore improve patient care (CAIPE n.d.). It was also felt that the students were enabled to reflect on - and gain a better understanding of - their own professional role.

\section{Real issues from practice uncovered}

The students felt that this assessment enabled them to see some of the real issues from practice around communication and the sharing of information.

It allowed me to see how communication can break down between professionals. Student feedback.

We could see what it would be like at work if you were trying to speak to someone working in a different department or organisation.

Student feedback.

As previously mentioned, the group members did not always find it easy to communicate with one another due to other pressures such as attending other academic sessions and attending practice, as well as their own personal commitments. The students felt that this was similar to professionals trying to make contact with one another across organisational- and teamboundaries, or when they were working different shift patterns. Some of the students felt that this made it much more real. There was a real awareness of communication issues that occurred in practice as a result of this group assessment. Students were also made aware of the issues around sharing information about service users and the balance of confidentiality versus 'needing to know' (Shaw, de Lusignan, and Rowlands 2005).

I was interested to find out about what information we can share with other people.

Student feedback.

This allowed the students to meet the Module Aims 3 and 4:

- To understand the importance of interprofessional communication and team working;

- To appreciate the complexity of delivering effective service user centred care in an interprofessional environment.

The staff members felt that, because the assessment mirrored the real issues that occur in practice with interprofessional working, it was a useful learning experience for the students, and that it prepared them well for interprofessional working. It allowed the students to understand how complex working with other professionals can be.

\section{Working together}

I can now see how I can work with other professionals.

Student feedback.

We can pull together to ensure better care.

Student feedback.

The students said that, because they were able to see patient pathway, they were also able to see how they could work together for the good of the patient. This enabled them to think in a positive way about the interprofessional team and team working (Mellor, Cottrell, and Moran 2013). The students could understand the expertise that each profession had, and also develop a greater understanding of the knowledge-base of the other professional groups.

I now know what knowledge other professions have.

Student feedback. 
Students could, therefore, see the importance of working together to improve the care given to the service user, and they acknowledged that they could not provide the complex care needed on their own.

Several students said that they found the experience enjoyable, and that they had made some new friends and had fun working together.

I have made some new friends from different groups as we got to know each other.

Student feedback.

One student described this as an 'unexpected bonus', and students felt that knowing someone from a different professional group would prove useful to them as they progressed as a student, as they could ask their colleague about things that they might need to know later on in their course.

The staff members felt that the students had engaged well with the team task and that interprofessional team working was evident.

The students worked together well as a team in all of the groups that I assessed. Staff feedback.

During the group presentation assessment, it was obvious that several of the groups had really 'gelled' together whilst completing the task, and this was pleasing to see.

\section{Making it relevant to all}

It was a real challenge to write suitable case studies that included all of the professional groups.

Staff feedback.

It was challenging to ensure that all of the professional groups had a role in each case study; this was a challenge for the module team. The students fed back that some professional groups had more involvement with their group's given case study.

It was difficult to see where we all fitted in to our case study.

Student feedback.

It was inevitable that this would happen, as some professional groups will not have as much involvement as others in any given care scenario.

However, it is important that students can see the relevance of the case study to their own professional practice. Any case studies used need to be relevant to all of the students in the group, and have something for them all to contribute so that they all feel included (Gilligan, Outram and Levett-Jones 2014).

Staff members also acknowledged that it was part of their role as facilitators to ensure that students saw the relevance of some of the case studies to their own profession, and that they should be able to do this in their discussions with the students when the case studies were given out.

We needed to be clearer in explaining the task so that the students understood where they fitted in.

Staff feedback.

The assessment was also a learning experience:

We learnt so much about each other.

Student feedback. 
Through the group case study assessment, the students were able to learn from one another and also learn about one another's roles. Therefore, the assessment also became a learning experience as the students had to produce a poster and learn what each other did (Stone 2010). This was the intention of the module team, so it was pleasing to see that the students acknowledged this in their questionnaire responses.

The staff were impressed by the standard of the group posters that were produced, and commented that there were some high quality posters and presentations which showed a good level of learning from the assessment.

There were some excellent posters.

Staff feedback.

Really good presentations which showed good knowledge.

Staff feedback.

Overall, both staff and students commented that the negotiation of marks went well and was also a good learning process for the students about working in a team and negotiation. Purchase (2000) and Stone (2010) both argue that peer assessment can be approached as a learning experience in itself, and that it allows students to develop reflective skills which can be useful for team working in the future.

Although I was nervous, I liked having the chance to choose how to mark my fellow students.

Student feedback.

The mark negotiation went better than I had anticipated and the students I assessed were very honest!'

Staff feedback.

Finally, the staff and students were also positive that the assessment process was all completed in one day.

\section{Conclusion}

On reflection, it is felt that the delivery of the module and the group assessment worked well and was positively evaluated by both the students and staff. The students have found it to be both a good learning experience as well as being a good way to assess an IPL module. The assessment was beneficial in terms of the process of working together in an interprofessional team, and the product - the group presentation and poster based on the case study.

The module delivery and assessment have met the aims and learning outcomes of the module. In working in interprofessional groups, the students had a 'real' experience of interprofessional working, facing the barriers and challenges to overcome which are similar to practice.

The students were able to learn from and about one another, reflect on their own professional role and understand the complexities of caring for service users within an interprofessional team. Friendships were also developed as a result of working together.

The students were encouraged to work together to care for the service user and to reflect on the service user pathway and the knowledge base of each profession involved. 


\section{Recommendations}

Staff members acknowledged that it was part of their role as facilitators to ensure that students saw the relevance of some of the case studies to their own profession, and that they should endeavour to do this in their discussions with the students when the case studies were given out at the start of the module.

For colleagues considering a similar assessment, it is recommended that you spend a significant amount of time planning and preparing for the assessment. Staff members and students need to be carefully briefed, and guidelines need to be clear and easy to understand. 


\section{References}

Ateah, C.A., Snow, W., Wener, P., MacDonald, L., Metge, C., Davis, P., Fricke, M., Ludwig, S., and Anderson, J. (2010) 'Stereotyping as a barrier to collaboration: Does interprofessional education make a difference?' Nurse Education Today, 31 (2), 208213 http://dx.doi.org/10.1016/j.nedt.2010.06.004

Barr, H., Koppel, I., Reeves, S., Hammick, M., and Freeth, D. (2005) Effective Interprofessional Education: Argument, Assumption and Evidence. Oxford: Blackwell and CAIPE https://doi.org/10.1002/9780470776445

Barr, H. and Low, H. (2012) Interprofessional Education in Pre-Registration Courses - A CAIPE Guide for Commissioners and Regulators of Education. London: CAIPE

Bell, L. and Allain, L. (2011) 'Exploring professional stereotypes and learning for interprofessional practice: An example from UK qualifying level social work education.' Social Work Education: The International Journal, 30 (3), 266-280 http://dx.doi.org/10.1080/02615479.2010.483726

CAIPE (n.d.) Welcome to CAIPE: The Centre for the Advancement of Interprofessional Education. [online] available from https://www.caipe.org/ [5 December 2016]

Cheng, W. and Warren, M. (2000) 'Making a difference: Using peers to assess individual students' contributions to a group project.' Teaching Higher Education, 5 (2), 243-255 https://doi.org/10.1080/135625100114885

Cooper, H., Carlisle, C., Gibbs, T., and Watkins, C. (2001) 'Developing an evidence base for interdisciplinary learning: A systematic review.' Journal of Advanced Nursing, 35 (2), 228-237 https://doi.org/10.1046/j.1365-2648.2001.01840.x

Department of Health (2000) The NHS Plan: A Plan for Investment, a Plan for Reform. London: Department of Health

Department of Health (2001) Making a Difference in Primary Care: The Challenge for Nurses, Midwives and Health Visitors - Case Studies from NHS regional conferences. London: Department of Health

Department of Health (2005) Creating a Patient-led NHS: Delivering the NHS Improvement Plan. London: Department of Health

Dunworth, M. (2007) 'Joint assessment in inter-professional education: A consideration of some of the difficulties.' Social Work Education, 26 (4), 414-422 https://doi.org/10.1080/02615470601081878

Gillham, B. (2000) Developing a Questionnaire. London: Continuum

Gilligan, C., Outram, S., and Levett-Jones, T. (2014) 'Recommendations from recent graduates in medicine, nursing and pharmacy on improving interprofessional education in university programs: A qualitative study.' BMC Medical Education, 14, 52 https://doi.org/10.1186/1472-6920-14-52

Hammick, M., Freeth, D., Koppel, I., Reeves, S., and Barr, H. (2007) 'A best evidence systematic review of interprofessional education: BEME Guide no. 9.' Medical Teacher 29 (8), 735-751 https://doi.org/10.1080/01421590701682576 
Kilminster, S., Hale, C., Lascelles, M., Morris, P., Roberts, T., Stark, P., Sowter, J., and Thistlethwaite, J. (2004) 'Learning for real life: Patient-focused interprofessional workshops offer added value.' Medical Education, 38 (7) 717-726 https://doi.org/10.1046/j.1365-2923.2004.01769.x

Lapkin, S., Levett-Jones, T., and Gilligan, C. (2013) 'A systematic review of the effectiveness of interprofessional education in health professional programs.' Nurse Education Today, 33 (2), 90-102 https://doi.org/10.1016/i.nedt.2011.11.006

Mandy, A., Milton, C., and Mandy, P. (2004) 'Professional stereotyping and interprofessional education.' Learning in Health and Social Care, 3 (3) 154-170 https://doi.org/10.1111/j.1473-6861.2004.00072.x

Martin, V., Charlesworth, J., and Henderson, E. (2010) Managing Health and Social Care. 2nd edn. Abingdon: Routledge

McKee, N., D’Eon, M., and Trinderk, K. (2013) 'Problem-based learning for inter-professional education: Evidence from an inter-professional PBL module on palliative care.' Canadian Medical Education Journal, 4 (1), e35-48

Mellor, R., Cottrell, N., and Moran, M. (2013) "Just working in a team was a great experience..." - Student perspectives on the learning experiences of an interprofessional education program.' Journal of Interprofessional Care. 27 (4), 292-297 https://doi.org/10.3109/13561820.2013.769093

Parsell, G. and Bligh, J. (1998) 'Interprofessional learning.' Postgraduate Medical Journal, 74, 89-95 https://doi.org/10.1136/pgmi.74.868.89

Purchase, H.C. (2000) 'Learning about interface design through peer assessment.' Assessment \& Evaluation in Higher Education, 25 (4), 341-352 https://doi.org/10.1080/026029300449245

Reeves, S. (2000) 'Community-based interprofessional education for medical, nursing and dental students.' Health and Social Care in the Community, 8 (4), 269-276 https://doi.org/10.1046/j.1365-2524.2000.00251.x

Shaw, A., de Lusignan, S., and Rowlands, G. (2005) 'Do primary care professionals work as a team: A qualitative study.' Journal of Interprofessional Care, 19 (4), 396-405 https://doi.org/10.1080/13561820500053454

Stephens, M., Robinson, L., and McGrath, D. (2013) 'Extending inter-professional learning through the use of a multi-disciplinary Wiki.' Nurse Education in Practice, 13 (6), 492 498 https://doi.org/10.1016/i.nepr.2013.01.009

Stone, J. (2010) 'Moving interprofessional learning forward through formal assessment.' Medical Education, 44 (4), 396-403 https://doi.org/10.1111/j.1365-2923.2009.03607.x

Welsh, J. (2012) 'Overcoming language barriers when teaching interprofessional groups.' Emergency Nurse, 20 (6), 33-36 https://doi.org/10.7748/en2012.10.20.6.33.c9345 